\title{
Secondary traumatic stress and compassion satisfaction mediate the association between stress and burnout among Korean hospital nurses: a cross-sectional study
}

Hyangkyu Lee ${ }^{1,2}$ (D) Wonhee Baek ${ }^{1,3,4^{*}}$ (D), Arum Lim ${ }^{1}$ (D), Dajung Lee ${ }^{4}$ (D) Yanghee Pang ${ }^{5}$ (D) and Oksoo Kim ${ }^{5,6}$ (D)

\begin{abstract}
Background: Burnout among nurses is a worldwide public health epidemic that adversely affects nurses' quality of life as well as the patient's outcomes. The aim of this study was to evaluate the influence of stress on nurses' burnout and to identify the mediating effects of secondary traumatic stress and compassion satisfaction among clinical nurses in South Korea.

Methods: A quantitative, cross-sectional study evaluated the survey data from 10,305 female registered hospital nurses who participated in the Korea Nurses' Health Study (KNHS) Module 5. The survey included a demographic questionnaire and the Professional Quality of Life version 5 (ProQOL 5). Bootstrap analyses (using the PROCESS macro) were employed to evaluate the mediating effect between variables.

Results: Stress was significantly associated with burnout and mediated by secondary traumatic stress and compassion satisfaction ( $\beta_{\text {indirect } 1}=0.185$, Bootstrap confidence interval (BS CI) $[0.175,0.194]$; $\beta_{\text {indirect } 2}=0.226$, BS Cl $[0.212,0.241]$, respectively). In addition, the magnitude of the indirect effects of compassion satisfaction was significantly greater than the magnitude of the indirect effects of secondary traumatic stress $\left(\beta_{\text {indirect }} 1-\beta_{\text {indirect } 2}=-\right.$ 0.042 , BS Cl $[-0.058,-0.026])$. The findings of this study indicate that the positive aspect (compassion satisfaction) of work experiences can offset the negative aspects (secondary traumatic stress), consequently reducing burnout level.

Conclusions: Our study findings suggest that a multidimensional approach to assessing nurse burnout and implementation of proper management will improve quality of life for nurses and help maintain positive attitudes and quality of patient care.
\end{abstract}

Keywords: Burnout, Compassion satisfaction, Mediation analysis, Secondary traumatic stress, Stress, The Korean nurses' health study

\footnotetext{
* Correspondence: heebakery@gmail.com; wonnie@kyungnam.ac.kr

'Department of Nursing, Graduate School of Yonsei Univeristy, Seoul, Republic of Korea

${ }^{3}$ Department of Nursing, Kyungnam University College of Health Sciences, Changwon 51767, Republic of Korea

Full list of author information is available at the end of the article
}

(c) The Author(s). 2021 Open Access This article is licensed under a Creative Commons Attribution 4.0 International License, which permits use, sharing, adaptation, distribution and reproduction in any medium or format, as long as you give appropriate credit to the original author(s) and the source, provide a link to the Creative Commons licence, and indicate if changes were made. The images or other third party material in this article are included in the article's Creative Commons licence, unless indicated otherwise in a credit line to the material. If material is not included in the article's Creative Commons licence and your intended use is not permitted by statutory regulation or exceeds the permitted use, you will need to obtain permission directly from the copyright holder. To view a copy of this licence, visit http://creativecommons.org/licenses/by/4.0/ The Creative Commons Public Domain Dedication waiver (http://creativecommons.org/publicdomain/zero/1.0/) applies to the data made available in this article, unless otherwise stated in a credit line to the data. 


\section{Background}

Burnout is a syndrome characterized by three dimensions: emotional exhaustion, depersonalization, and reduced personal accomplishment [1]. People who experience burnout are more likely to leave their jobs; in fact, some resign from their jobs without hesitation. Even if they stay in their jobs, their job performance, efficacy, and job satisfaction are significantly decreased. Moreover, burnout adversely affects physical symptoms, like pain, as well as mental health, including depression and anxiety [2, 3]. Indeed, burnout was recently classified as an occupational phenomenon in the 11th Revision of the International Classification of Diseases (ICD-11) [4] indicating that burnout has emerged as a worldwide health problem in workplaces.

Numerous studies have demonstrated an association between work-related or personal stress and burnout [5-7]. Nurses perform tasks that require professional knowledge and a high level of technical skills; they are also required to cope with patients who have various health needs. Furthermore, nurses experience elevated stress in the course of providing continuous care for patients $24 \mathrm{~h}$ a day, as well as contacting and communicating with many medical staff and family members [8-10]. This results in chronic stress build-up, leading to nurses' burnout [11]. Stress affects the incidence of burnout, and that burnout eventually negatively affects nurses' general health [12]. In addition, increased burnout is related to lower quality of nursing care, lower patient satisfaction, and higher healthcare-associated infection rates [13].

Nurses experience secondary traumatic stress (STS), defined as negative behavior and emotion driven by fear and work-related trauma, in the course of caring for patients. STS occurs when nurses are traumatized by their work, and is usually associated with a particular event [14]. However, nurses also experience compassion satisfaction (CS) which is a positive emotion that reflects the rewards of caring for others. CS occurs as a result of working with patients and families and experiencing positive emotional rewards such as fulfillment, joy, and hope [15]. As such, professional quality of life (ProQOL) encompass positive and negative aspects; thus, when discussing work-related quality of life of nurses, it is necessary to consider the influential effects or interactive dynamics between burnout, secondary traumatic stress, and compassion satisfaction.

A study conducted in China indicated that, after adjusting for the covariates, longer working shifts were associated with higher STS [16]. Another study conducted in Israel demonstrated that stress and CS were negatively correlated [17]. Moreover, a number of studies reveal that stress is related to or affects STS and CS $[18,19]$. In addition, positive (CS) or negative (STS) feelings experienced by nurses may affect burnout [2022]. In a meta-analysis by Zhang et al. [22] which included 11 studies burnout and STS displayed a strong positive correlation $(\mathrm{r}=0.59)$, and burnout and CS was moderately negatively correlated $(r=-0.446)$. However, there is a limited number of studies confirming the relationship between stress and STS and CS in nurse burnout [23-25] and it remains unclear what role of STS and CS play in this relationship. Hence, we sought to elucidate how STS and CS function as mediators of burnout.

A high turnover or resignation of nursing staff results in a tremendous nursing shortage [26] and burnout has a major impact on this outcome. According to a report from the National Academies of Science at the end of 2019, 35\% of US nurses experience substantial symptoms of burnout [10]. The situation in Korea is more serious, a systematic review of burnout confirmed that Korean nurses had increased burnout compared to nurses in other countries [27]. In addition, the national survey of health workers in Korea reported that physical and psychological burnout was ranked third as the reason for resigning or changing jobs among nursing staff [28]. Although the Korean nurses' turnover rate is substantially high, no studies have employed national representative sampling and/or factors affecting the burnout of Korean nurses in a clinical setting. Therefore, to reduce burnout among Korean nurses, it is necessary to identify the factors that affect burnout and the relationship between them.

\section{Methods}

This research followed the Strengthening the Reporting of Observational Studies in Epidemiology (STROBE) guideline [29].

\section{Aim}

The purpose of this study was to identify whether stress affects burnout and to confirm whether STS and CS play a mediating role in the relationship between stress and burnout among nurses in Korea. The hypothesis of this study was as follows: Elevated stress is associated with high burnout and the association between stress and burnout is mediated through STS and CS.

\section{Study design and sample}

The Korea Nurses' Health Study (KNHS) was a prospective cohort study of Korean female registered nurses that examined the effects of occupational, environmental, and lifestyle risk factors on the health of Korean women [30]. The Nurses' Health Study (NHS) was a cohort study of United States nurses that began in 1976 [31]. The KNHS is a Korean version of the NHS and is based on the study protocol and questions used in the NHS3. The participants of the KNHS were selected from 
among those who were living in Korea, were between 20 and 45 years of age, and who had at least one year of nursing experience. There were 157,569 women of childbearing age who were registered with the Korean Nurses Association (KNA). The sample size was calculated as 17,431 with a significance level of 0.05 and a permissible error of $1 \%$ by random sampling based on the parameters of the population. The target sample size for KNHS was 20,000 female nurses. Module 1 (the baseline survey) was implemented in 2013 and subsequent follow-up surveys were conducted every 6-8 months. Module 5 was conducted in 2016. Nurses were involved in the research through several channels, including social media and print advertising, and surveys were conducted through the KNHS website. Nurses not working in module 5 and nurses not working in hospitals were excluded from the analysis.

\section{Measurements}

\section{Demographic characteristics}

Eligible registered nurses completed a web-based selfreported questionnaire including data for age, nursing education level, marital status (never married or married), hospital size, department (inpatient, intensive care unit (ICU)/emergency department (ED), operating room, outpatient, management, or others), clinical nursing experience (under 3 years, 3-5 years, $6-10$ years or, more than 11 years), work overtime (yes or no), employment (full time or part time), rotational night shift (yes or no) and annual income converted to US dollars per year.

\section{Burnout, secondary traumatic stress, and compassion satisfaction}

The Professional Quality of Life Scale (ProQOL) version 5 developed by Stamm [14] was used to evaluate the positive and negative aspects of professionals who work to help others. The ProQOL5 is composed of three subscales: STS, CS, and burnout. Each subscale measures separate aspects and cannot be combined [14], has 10 questions rated on a 5-point Likert scale, and has a score range of 10 to 50 points. Scores $<22$ points are considered "low", 23-41 points "moderate", and $>42$ points "high"; the higher the score, the higher the CS, STS, and burnout. ProQOL version 5 developed by Stamm is accessible to the public via web link [32]. The reliability and validity of the ProQOL5 have been validated among Korean nurses [33]. The internal consistency (Cronbach's $\alpha$ ) was previously reported as 0.72 for the STS subscale, 0.89 for the CS subscale, and 0.73 for the burnout subscale [33].

\section{Stress}

Stress was measured by the perceived stress scale (PSS) developed by Cohen and Williamson [34]. PSS assesses subjective perceptions of stress over the past month. It consists of a total of 10 items rated on a 5-point Likert scale ranging from 4 (fairly frequent) to 0 (none). Scores range from 0 to 40, with higher scores indicating higher levels of stress. Recently, this measure has shown evidence of good psychometric properties in nurse populations $[35,36]$. The Cronbach's $\alpha$ coefficient of the original study was 0.78 .

\section{Statistical analysis}

All statistical analyses were performed using $R$, version 4.4.0 (R Foundation for Statistical Computing) and $p<0.05$ was considered statistically significant. Descriptive statistics, such as percentages and mean of demographic characteristics were calculated. To identify factors associated with burnout prior to the regression analysis, independent $\mathrm{t}$ tests, ANOVAs, and Bonferroni multiple comparisons were performed according to the characteristics of the variables. To identify the correlation between stress, STS, CS, and burnout, Pearson correlations were performed.

The associations between the study variables were analyzed using linear regression analyses and to correct for Type I error due to multiple comparisons, tests were performed at the significance level to which Bonferroni correction was applied. The mediating role of stress and STS, and stress and CS were tested using bootstrap analyses with a PROCESS macro developed by Hayes [37]. In the parallel multiple mediator model, there are three pathways by which the independent variable can be associated with the dependent variable: the direct pathway $\left(c^{\prime}\right)$ leads directly from the independent to the dependent variable, while the indirect pathway $\left(\left(a_{1} \times b_{1}\right)\right.$ and $\left(a_{2} \times b_{2}\right)$ ) incorporates a mediating variable (Fig. 1 ). First, we tested the indirect effect. After the indirect effect was proven, the direct effect was tested. If a direct effect was identified, it indicated that the relationship between $\mathrm{X}$ and $\mathrm{Y}$ was partially mediated by M1 and M2 (Fig. 1). The indirect and direct effects were considered statistically significant if the $95 \%$ confidence interval of the bootstrap estimate did not include zero. The bootstrap method is preferred in mediation analysis because it uses resampling with replacement and does not require the assumption of normality. Therefore, an accurate inferential test is possible and power is high [37]. All analyses were adjusted for marital status, final education, clinical nursing experience, hospital size, department, overtime work, and rotational night shifts.

\section{Results}

\section{General demographics and characteristics}

In this study, among 11,526 nurses who completed KNHS Module 5, we excluded 1206 who did not work at a hospital and 15 who provided incomplete data. The final sample available for analysis included 10,305 nurses. The demographic and work-related 


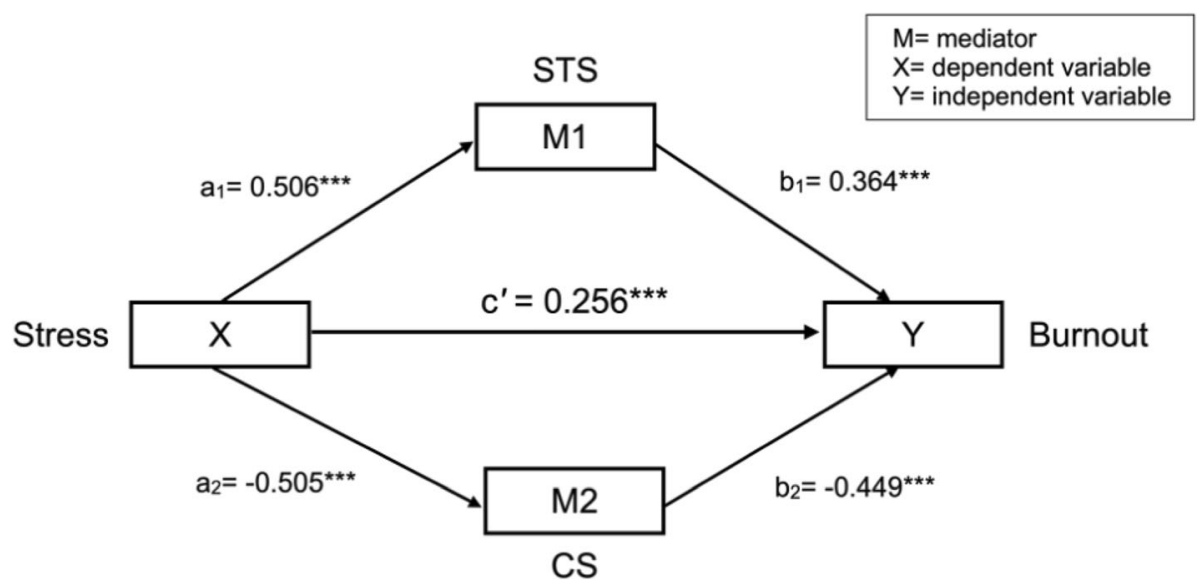

Fig. 1 Path diagram for the model. Path coefficients were non-standardized estimates. STS = secondary stress trauma; CS = compassion satisfaction; ${ }^{* * *} p<.001$

characteristics of nurses are presented in Table 1 . This study included 10,305 female nurses with a mean age of $32.8(\mathrm{SD}=6.06)$ years $($ range $=23-51), 59.9 \%$ of respondents held a bachelor's degree. The largest percentage of nurses worked in inpatient departments (40\%).

\section{Burnout according to general characteristics}

Cronbach's $\alpha$ coefficient of burnout in our study was 0.73. Burnout levels, according to general characteristics of the participants, are presented in Table 1 . In terms of demographic characteristics, there were significant differences in education level $(F=64.89, d f=2, p<.001)$ and marital status $(t=21.13, p<.001)$. The group of nurses with diploma degrees experienced higher burnout than nurses with a bachelor's, or master's or higher degree. Never-married nurses experienced higher burnout, with a score of $27.9(\mathrm{SD}=5.0)$.

For work-related characteristics, nurses working in a hospital with 600-999 beds had the highest burnout score of $27.0(\mathrm{SD}=5.2)$ compared to nurses working in a hospital with $30-299$ beds $(F=6.83, d f=3, p<.001)$ and those working in inpatient or ICU/ED departments had the highest scores of $27.5(\mathrm{SD}=5.2)$, and $27.3(\mathrm{SD}=5.1)$, respectively $(F=70.75, d f=5, p<.001)$. In addition, for nurses with less than 6 years of working experience $(F=$ $116.5, d f=3, p<.001)$, overtime work $(t=-11.17$, $p<.001)$, rotational night shifts $(t=-16.66, p<.001)$, and lower annual income $(t=10.58, p<.001)$, burnout scores were relatively higher.

\section{Burnout level and relationship among stress, secondary traumatic stress, and compassion satisfaction}

Cronbach's $\alpha$ coefficients for stress, STS, and CS in our study were $0.7,0.72$, and 0.89 , respectively. The mean stress score of 10,305 nurses was $17.7(\mathrm{SD}=4.5)$, the mean STS score was $24.2(\mathrm{SD}=5.8)$, the mean CS score was $30.9(\mathrm{SD}=7.1)$, and the mean burnout score was $26.7(\mathrm{SD}=5.3)$. There was a positive relationship between stress and burnout as well as stress and STS $(r=$ $0.60, p<.001 ; r=0.40, p<.001$, respectively). Stress and CS were negatively correlated $(r=-0.35, p<.001)$. Burnout and STS were positively correlated $(r=0.47$, $p<.001)$ while burnout and CS were negatively correlated $(r=-0.67, p<.001)$ (Table 2$)$.

\section{Multiple linear regression analysis}

Descriptive statistics for stress, STS, and CS for the multiple linear regression analysis are shown in Table 3. We performed a multiple linear regression using stress as the predictor variable for STS, CS, and burnout. The adjusted $\mathrm{R}$ squares for these regression models were 19 , 20 , and $73 \%$, respectively. Factors affecting burnout included stress, STS, CS, marital status, hospital size, work overtime, and a higher stress level was associated with a higher burnout level $(\beta=0.256, p<.001)$. Factors affecting STS included marital status, hospital size, department, work overtime, and a higher stress level was associated with higher STS $(\beta=0.506, p<.001)$. Factors affecting CS included marital status, final education, department, clinical nursing experience, and a higher stress level was associated with lower CS levels $(\beta=-0.505, p<.001)$.

\section{Testing for the mediator}

Table 4 presents the results of the bootstrap analyses for the mediation analysis. STS and CS had indirect effect between stress and burnout ( $\beta_{\text {indirect } 1}=0.185$, Bootstrap confidence interval $(\mathrm{BS} C I)[0.175,0.194]$; $\beta_{\text {indirect } 2=}=$ 0.226 , BS $C I[0.212,0.241]$, respectively). Stress had a direct effect of burnout ( $\beta_{\text {direct } c^{\prime}}=0.256$, BS CI $[0.240$, 0.272]) (Fig. 1). Therefore, STS and CS partially mediated the relationship between stress and burnout. In addition, the indirect effect of stress on burnout with CS 
Table 1 Burnout according to Korean nurses' demographics and characteristics $(N=10,305)$

\begin{tabular}{|c|c|c|c|c|c|c|}
\hline & & & Burnot & & & \\
\hline & $N$ & $\%$ & Mean & $S D$ & $F$ or $t$ & $p$ \\
\hline Education & & & & & 64.89 & $<.001$ \\
\hline Diploma (3-yr course) ${ }^{a}$ & 2706 & 26.2 & 27.2 & 5.3 & & $b, c<a^{\$}$ \\
\hline Bachelor's ${ }^{b}$ & 6168 & 59.9 & 26.9 & 5.2 & & $c<b^{\$}$ \\
\hline Master's or higher ${ }^{c}$ & 1431 & 13.9 & 25.3 & 5.1 & & \\
\hline Marital status & & & & & 21.13 & $<.001$ \\
\hline Never married & 4873 & 47.3 & 27.9 & 5.3 & & \\
\hline Married & 5432 & 52.7 & 25.7 & 5.0 & & \\
\hline Hospital size (number of beds) & & & & & 6.83 & $<.001$ \\
\hline $30-299^{a}$ & 2390 & 23.2 & 26.4 & 5.2 & & $a<b^{\$}$ \\
\hline $300-599$ & 2187 & 21.2 & 26.7 & 5.3 & & \\
\hline $600-999^{b}$ & 3698 & 35.9 & 27.0 & 5.2 & & \\
\hline 1000 or more & 2030 & 19.7 & 26.8 & 5.3 & & \\
\hline Department & & & & & 70.75 & $<.001$ \\
\hline Inpatient ${ }^{a}$ & 4123 & 40.0 & 27.5 & 5.2 & & $c, d, e, f<a^{\$}$ \\
\hline ICU/ED ${ }^{b}$ & 1629 & 15.8 & 27.3 & 5.1 & & $c, d, e, f<b^{\$}$ \\
\hline Operating room ${ }^{c}$ & 996 & 9.7 & 26.5 & 5.0 & & $e, f<c^{\$}$ \\
\hline Outpatient $^{d}$ & 1723 & 16.7 & 26.2 & 5.3 & & $e<d^{\$}$ \\
\hline Management ${ }^{\mathrm{e}}$ & 1046 & 10.2 & 24.7 & 5.0 & & $e<f^{\$}$ \\
\hline Others $^{f}$ & 788 & 7.6 & 25.6 & 5.2 & & \\
\hline Clinical nursing experience (yrs) & & & & & 116.50 & $<.001$ \\
\hline under $3^{a}$ & 460 & 4.5 & 28.3 & 5.3 & & $c, d<a^{\$}$ \\
\hline $3-5^{b}$ & 1724 & 16.7 & 27.9 & 5.1 & & $c, d<b^{\$}$ \\
\hline $6-10^{c}$ & 3714 & 36.0 & 27.3 & 5.3 & & $d<c^{\$}$ \\
\hline 11 or more $^{d}$ & 4407 & 42.8 & 25.7 & 5.0 & & \\
\hline Work overtime & & & & & -11.17 & $<.001$ \\
\hline No & 1196 & 11.6 & 25.2 & 5.2 & & \\
\hline Yes & 9109 & 88.4 & 27.0 & 5.2 & & \\
\hline Employment & & & & & -1.36 & .174 \\
\hline Full-time & 9611 & 93.3 & 26.7 & 5.2 & & \\
\hline Part-time & 694 & 6.7 & 27.0 & 5.4 & & \\
\hline Rotational night shift & & & & & -16.66 & $<.001$ \\
\hline No & 4538 & 44.0 & 25.8 & 5.1 & & \\
\hline Yes & 5767 & 56.0 & 27.5 & 5.2 & & \\
\hline Income (1000 USD)/year & & & & & 10.58 & $<.001$ \\
\hline 36.9 or less & 7543 & 73.2 & 27.1 & 5.2 & & \\
\hline 37 or more & 2762 & 26.8 & 25.8 & 5.2 & & \\
\hline
\end{tabular}

ED emergency department, $h$ hours, ICU intensive care unit, $S D$ standard deviation, yrs. years, $\$=$ Bonferroni post hoc test

If there were a difference in the mean value for demographics and characteristics, a post-hoc analysis was performed using the Bonferroni method. For categories with significant differences, a, b, c, d, and e were given as superscript letters and relative sizes were indicated

as the mediator is greater than the indirect effect of stress on burnout with STS as the mediator ( $\beta_{\text {indirect } 1^{-}}$ $\beta_{\text {indirect } 2}=-0.042$, BS CI $\left.[-0.058,-0.026]\right)$. The proportion of mediating effects with total effect was $61 \%$ (BS CI $[0.596,0.636])$.

\section{Discussion}

In this study, we evaluated the influence of stress on burnout among Korean nurses and examined the mediating effects of STS and CS. The results from the mediation model indicated that stress had not only a direct 
Table 2 Level and relation among stress, secondary traumatic stress, compassion satisfaction, and burnout among Korean nurses $(\mathrm{N}=10,305)$

\begin{tabular}{|c|c|c|c|c|c|c|}
\hline \multirow[b]{2}{*}{ Variable } & \multirow[b]{2}{*}{ Mean } & \multirow[b]{2}{*}{$S D$} & \multicolumn{4}{|c|}{ Pearson correlation coefficients } \\
\hline & & & Stress & STS & CS & Burnout \\
\hline Stress & 17.7 & 4.5 & 1.00 & & & \\
\hline Secondary traumatic stress & 24.2 & 5.8 & 0.40 & 1.00 & & \\
\hline Compassion satisfaction & 30.9 & 7.1 & -0.35 & 0.04 & 1.00 & \\
\hline Burnout & 26.7 & 5.3 & 0.60 & 0.47 & -0.67 & 1.00 \\
\hline
\end{tabular}

SD standard deviation, STS secondary traumatic stress, CS compassion satisfaction

effect on burnout among Korean nurses but also an indirect effect on burnout via STS and CS. Additionally, the magnitude of the indirect effects of CS was significantly greater than STS.

Based on a nationwide representative sample, the mean burnout score of Korean nurses was 26.7 (5.2) indicating moderate burnout. In previous studies that used the same measurement tool, the mean burnout score for American nurses was 23.66-25.63 which was lower than for nurses in Korea [23-25], while the mean burnout score of Chinese nurses was 26, similar to nurses in Korea [38]. The prevalence rate of overtime work in Korean nurses was $88 \%$, which was considerably higher than the rates observed in China (55\%) [39] and Europe (27\%) [40]. Moreover, the number of patients per nurse was higher than in Thailand, China, the US, and European countries; a higher nurse to patient ratio (1:12.3) is associated with lower quality care and poor patient safety [41]. In fact, the RN-to-population was 3.5:1000, which is less than half of the mean (7.2:1000) of the Organization for Economic Cooperation and Development (OECD) countries [28].

Our study results revealed a strong positive correlation between stress and burnout, consistent with previous research. In particular, work-related stress is considered a major concern, because burnout symptoms are associated with stress due to job demands and lack of organizational support [6,7]. Although nurses primarily treat patients' illnesses and enhance their well-being, they are also required to assist with patients' circumstances such as family dynamics and social support systems. In this process, nurses who provide 24-h care face difficulty with additional tasks, such as handling unexpected system problems or role conflicts with other medical staff [9]. Conflicts between the patient's circumstance, institutional system/support, and professional responsibilities of nurses often result in increased overtime work and burnout $[8,27,41]$.

On the other hand, Khamisa et al. [5] reported that personal stress rather than work-related stress was a better predictor of burnout and general health. Indeed, it has been reported that when there was a problem with their family, nurses were less able to concentrate on work, which increased burnout [42]. However, the results of our regression analysis revealed that married nurses had lower levels of burnout after accounting for other variables (Table 3). This result supports previous findings that work-related stress or compassion fatigue were alleviated by supportive networks from family and community $[43,44]$. There are also gender effects on the prevalence of burnout. Most Korean nurses (95.2\%) are female [28] and are responsible not only for work but also for family obligations such as childcare at home. Consequently, they may have to endure stressful situations both inside and outside the workplace [45]. Therefore, we should consider family-work conflict (e.g., how personal stress affects burnout) or how much job stress is buffered by personal situations when individuals perceive situations as stressful. However, since this study is a cross-sectional study, it is difficult to be certain whether perceived stress affects burnout or whether burnout affects perceived stress. Therefore, further large-scale longitudinal study is needed to determine the effect on burnout according to stress.

Taken together, the results of these studies suggest that stress assessment and management are an essential approach to prevent burnout. A recent meta-analysis supported the notion that stress management is one of the major effective interventions to prevent and reduce burnout of physicians [46]. However, it is also necessary to consider the relationship between burnout and stress as a whole given the difficulty with categorizing stress into uniquely "job" or "individual" dimensions [44]. To address nurses' stress management it is necessary to develop a comprehensive plan that encompasses several characteristics, rather than dividing stress into dimensions and presenting partial solutions.

In this study, we confirmed that STS has an indirect effect on the relationship between stress and burnout. Higher stress levels resulted in higher burnout levels and the additional STS further increased burnout. This finding is consistent with those of a previous study in which nurses who had insufficient time to care for patients due to workload experienced high STS [19]. STS progresses rapidly [14] while burnout progresses gradually due to high workload or an unsupportive work environment 
Table 3 Model estimates for stress, secondary traumatic stress, and compassion satisfaction by multiple linear regression analysis among Korean nurses $(\mathrm{N}=10,305)$

\begin{tabular}{|c|c|c|c|c|c|c|c|c|c|}
\hline \multirow{3}{*}{$\begin{array}{l}\text { Variable } \\
\text { Antecedent }\end{array}$} & \multicolumn{9}{|c|}{ Consequent } \\
\hline & \multicolumn{3}{|c|}{ M1: STS } & \multicolumn{3}{|l|}{ M2: CS } & \multicolumn{3}{|c|}{ Y: Burnout } \\
\hline & Coef & s.e & $p$ & Coef & s.e & $p$ & Coef & s.e & $p$ \\
\hline Stress & 0.506 & 0.012 & $<.001$ & -0.505 & 0.014 & $<.001$ & 0.256 & 0.007 & $<.001$ \\
\hline \multicolumn{10}{|l|}{ Mediator } \\
\hline Mediator 1: STS & - & - & - & - & - & - & 0.364 & 0.005 & $<.001$ \\
\hline Mediator 2: CS & - & - & - & - & - & - & -0.449 & 0.004 & $<.001$ \\
\hline \multicolumn{10}{|l|}{ Covariates } \\
\hline \multicolumn{10}{|l|}{ Marital } \\
\hline Married & $\operatorname{Ref}(0)$ & & & $\operatorname{Ref}(0)$ & & & $\operatorname{Ref}(0)$ & & \\
\hline Never married & -0.471 & 0.121 & $<.001$ & -1.785 & 0.147 & $<.001$ & 0.412 & 0.063 & $<.001$ \\
\hline \multicolumn{10}{|l|}{ Education } \\
\hline Over master & $\operatorname{Ref}(0)$ & & & $\operatorname{Ref}(0)$ & & & $\operatorname{Ref}(0)$ & & \\
\hline Diploma & -0.427 & 0.192 & 0.026 & -1.423 & 0.234 & $<.001$ & -0.017 & 0.100 & 0.865 \\
\hline Bachelor & -0.206 & 0.166 & 0.216 & -1.126 & 0.203 & $<.001$ & -0.069 & 0.087 & 0.428 \\
\hline \multicolumn{10}{|l|}{ Hospital size } \\
\hline $30-299$ & $\operatorname{Ref}(0)$ & & & $\operatorname{Ref}(0)$ & & & & & \\
\hline $300-599$ & 0.295 & 0.157 & 0.060 & -0.074 & 0.192 & 0.699 & 0.204 & 0.082 & 0.013 \\
\hline 600-999 & 0.517 & 0.146 & $<.001$ & 0.058 & 0.178 & 0.746 & 0.313 & 0.076 & $<.001$ \\
\hline 1000 or more & 0.445 & 0.166 & 0.007 & 0.039 & 0.203 & 0.847 & 0.219 & 0.087 & 0.012 \\
\hline \multicolumn{10}{|l|}{ Department } \\
\hline Inpatient & $\operatorname{Ref}(0)$ & & & $\operatorname{Ref}(0)$ & & & $\operatorname{Ref}(0)$ & & \\
\hline ICU/ED & 0.028 & 0.154 & 0.858 & 0.052 & 0.188 & 0.006 & -0.065 & 0.080 & 0.417 \\
\hline Operating R. & -1.412 & 0.188 & $<.001$ & -0.219 & 0.223 & 0.341 & 0.009 & 0.098 & 0.928 \\
\hline Outpatient & -1.118 & 0.181 & $<.001$ & 0.040 & 0.221 & 0.856 & -0.115 & 0.094 & 0.223 \\
\hline Management & -1.506 & 0.216 & $<.001$ & 1.860 & 0.264 & $<.001$ & 0.122 & 0.113 & 0.282 \\
\hline Others & -1.080 & 0.221 & $<.001$ & 0.991 & 0.270 & $<.001$ & -0.116 & 0.116 & 0.318 \\
\hline \multicolumn{10}{|c|}{ Clinical nursing experience } \\
\hline Under $3 \mathrm{yr}$ & $\operatorname{Ref}(0)$ & & & $\operatorname{Ref}(0)$ & & & $\operatorname{Ref}(0)$ & & \\
\hline $3-5 y r$ & -0.548 & 0.275 & 0.046 & 0.200 & 0.336 & 0.550 & -0.330 & 0.143 & 0.021 \\
\hline $6-10 y r$ & -0.133 & 0.260 & 0.609 & 0.718 & 0.318 & 0.024 & -0.182 & 0.136 & 0.181 \\
\hline 11 or more & 0.097 & 0.271 & 0.722 & 2.336 & 0.331 & $<.001$ & 0.048 & 0.142 & 0.736 \\
\hline \multicolumn{10}{|l|}{ Work overtime } \\
\hline No & $\operatorname{Ref}(0)$ & & & $\operatorname{Ref}(0)$ & & & $\operatorname{Ref}(0)$ & & \\
\hline Yes & 1.107 & 0.166 & $<.001$ & 0.247 & 0.203 & 0.224 & 0.416 & 0.087 & $<.001$ \\
\hline \multicolumn{10}{|c|}{ Rotational night shift } \\
\hline No & $\operatorname{Ref}(0)$ & & & $\operatorname{Ref}(0)$ & & & $\operatorname{Ref}(0)$ & & \\
\hline Yes & 0.348 & 0.143 & 0.015 & -0.017 & 0.174 & 0.924 & -0.065 & 0.745 & 0.381 \\
\hline$R^{2}$ & 0.19 & & & 0.20 & & & 0.73 & & \\
\hline Adjusted $R^{2}$ & 0.19 & & & 0.20 & & & 0.73 & & \\
\hline Residual SE & $5.21(d f$ & & & $6.36(d f$ & & & $2.72(d f$ & & \\
\hline F & $139.2(p$ & & & 153.8 & & & 1482 & & \\
\hline
\end{tabular}

STS secondary trauma stress, CS compassion satisfaction, $Y$ dependent, Coef coefficient, s.e or SE standard error, ICU intensive care unit, ED Emergency department, Operating $R$ Operating room, $d f$ degrees of freedom 
Table 4 Mediation analyses of secondary traumatic stress and compassion satisfaction in the association between stress and burnout

\begin{tabular}{llll}
\hline Effect & Equation & Estimate & 95\% Bootstrap Cl \\
\hline Indirect 1 & $\left(\mathrm{a}_{1}\right)^{*}\left(\mathrm{~b}_{1}\right)$ & 0.185 & 0.175 to 0.194 \\
Indirect 2 & $\left(\mathrm{a}_{2}\right)^{*}\left(\mathrm{~b}_{2}\right)$ & 0.226 & 0.212 to 0.241 \\
Direct & $\mathrm{c}^{\prime}$ & 0.256 & 0.240 to 0.272 \\
Contrast & Indirect 1 - Indirect 2 & -0.042 & -0.058 to -0.026 \\
Indirect & Indirect 1 + Indirect 2 & 0.411 & 0.395 to 0.429 \\
Total & Indirect + Direct & 0.667 & 0.648 to 0.690 \\
Prop.mediated & Indirect / Total & 0.616 & 0.596 to 0.636 \\
\hline
\end{tabular}

$\mathrm{Cl}$ confidence interval, Prop.mediated proportion of indirect effect to total effect

[27]. Because STS can be prevented and ameliorated [47], medical institutions need to address STS appropriately and take early, preventative measures to ensure that burnout is not exacerbated.

We also confirmed that CS has a partial mediating effect on the relationship between stress and burnout. This was consistent with the results of a previous study investigating the negative correlation between burnout and CS [20]. CS is a positive outcome of working as a nurse, however, its effects are reduced when experiencing significant stressful situations and, consequently, burnout will occur. Conversely, even if there is a stressful situation, a nurse experiencing CS can counterbalance the relationship between stress and burnout. In particular, the indirect effect of CS was greater than the indirect effect by STS (Table 4) resulting in reducing burnout among nurses. Moreover, high empathy reduces a nurse's burnout [38], which can be interpreted as an additional positive effect experienced by nurses who experience a sense of reward from helping others, even in difficult situations. Therefore, it would be effective to establish a management strategy to reduce the nurses' burnout in a way that reduces stress and increases CS. Chen et al. (2018) reported that CS was reinforced by workplace support such as regular debriefing with managers and priests for nurse staff, and CS was associated with personality traits (conscientiousness, affability and emotional stability). In addition, an emotional regulation training program that includes psychoeducation, progressive muscle relaxation, and nonjudgmental awareness has been demonstrated to increase CS [48]. Therefore, an improved organizational approach that encourages a dynamic environment, such as group support or coaching, could help nurses engage with CS.

\section{Limitations}

There are several limitations to this study. First, psychological characteristics are also influential factors that affect burnout [27], but these were not included in the survey. Second, the hospital or manager's support and relationships with colleagues could not be investigated. Third, PSS is a tool to measure how to perceive stress in stress-related processing, it could not be clearly determined whether the PSS was the appropriate scale for assessing occupational or personal related stress, or if it measured a combination of both. Fourth, the KNHS is a prospective cohort study of female nurses focusing on the effects of occupational, environmental, and lifestyle risk factors on the health of Korean women [30]; thus, male nurses are not represented in the analysis. Although the proportion of male nurses in Korea is extremely low (4.8\%) [28] their burnout also needs to be addressed. Fifth, this is a cross-sectional and secondary analysis study, so the results have limited use for making conclusions about causal relationships. These limitations should be addressed in further studies to confirm factors that influence nurses' burnout.

\section{Conclusion}

This study was the first investigation of the relationship between stress, STS, CS, and burnout among Korean nurses using a nationwide representative sample. We observed that burnout was associated with nurses' stress. Comprehensive identification of the causes increasing personal and work-related stress and appropriate interventions will help to reduce nurses' burnout. We found that STS and CS may exert partial mediating effects on the relationship between stress and burnout in this study, therefore, a multidimensional approach, including reduction of STS and promoting CS within a stressreducing intervention program will be more effective.

\section{Abbreviations}

CS: Compassion Satisfaction; ER: Emergency Room; ICD-11: 11th Revision of the International Classification of Diseases; ICU: Intensive Care Unit; KNA: Korean Nurses Association; NHS: Nurses' Health Study; KNHS: Korea Nurses' Health Study (KNHS); OECD: Organization for Economic Cooperation and Development; ProQOL 5: Professional Quality of Life Version 5; PSS: Perceived Stress Scale; STROBE: Strengthening the Reporting of Observational Studies in Epidemiology; STS: Secondary Traumatic Stress

\section{Acknowledgements}

Special thanks must go to the Korean Nurses who faithfully participated in this survey.

\section{Authors' contributions \\ $H L, W B, A L, Y P$, and OK designed this study. Literature search was performed by $H L, W B, A L$, and $D L$. Data analysis was carried out by $H L$ and WB. HL, WB, and OK contributed to data interpretation. $H L, W B, A L, Y P, O K$ and DL contributed to writing and approval of the manuscript. Critical revisions for important intellectual content were carried out by $\mathrm{HL}, \mathrm{WB}, \mathrm{YP}$, and OK.}

\section{Funding}

The KNHS received financial support to conduct research at the Korea National Institute of Health from the Korea Centers for Disease Control and Prevention (KCDC). This study was supported by a grant from the KCDC (No: 2016ER630500 and 2016ER630501). 


\section{Availability of data and materials}

The datasets are not publicly accessible and freely available since the use and analysis of the pooled data and the publication of any research findings and study results out of it are restricted by contract with the Korea Centers for Disease Control and Prevention (KCDC). The KCDC is planning on opening this data to the public in the future.

\section{Declarations}

\section{Competing interesting}

The authors declare that they have no actual or potential conflicts of interests.

\section{Ethics approval and consent to participate}

The study design was approved by the Institutional Review Board of Ewha Woman's University (No. 117-4). Anonymity and confidentiality were assured, and the participants' informed consent was obtained as part of the online survey.

\section{Consent for publication}

Not applicable.

\section{Author details}

'Department of Nursing, Graduate School of Yonsei Univeristy, Seoul, Republic of Korea. ${ }^{2}$ Mo-Im Kim Nursing Research Institute, College of Nursing, Yonsei University, Seoul, Republic of Korea. ${ }^{3}$ Department of Nursing, Kyungnam University College of Health Sciences, Changwon 51767, Republic of Korea. ${ }^{4}$ Severance Hospital, Seoul, Republic of Korea. ${ }^{5}$ College of Nursing, Ewha Womans University, Seoul, Republic of Korea. ${ }^{6}$ Ewha Research Institute of Nursing Science, Seoul, Republic of Korea.

\section{Received: 29 October 2020 Accepted: 10 June 2021}

Published online: 30 June 2021

\section{References}

1. Maslach C, Jackson SE. Burnout in organizational settings. Appl Soc Psychol Annu. 1984:5:133-53.

2. Maslach C, Schaufeli WB, Leiter MP. Job burnout. Annu Rev Psychol. 2001; 52(1):397-422. https://doi.org/10.1146/annurev.psych.52.1.397.

3. Rudman A, Gustavsson JP. Early-career burnout among new graduate nurses: a prospective observational study of intra-individual change trajectories. Int J Nurs Stud. 2011;48(3):292-306. https://doi.org/10.1016/j. ijnurstu.2010.07.012.

4. World Health Organization [Internet]. 2019. Burn-out an "occupational phenomenon": international classification of diseases. https://www.who.int/ mental_health/evidence/burn-out/en/. Accessed 15 January 2021.

5. Khamisa N, Peltzer K, llic D, Oldenburg B. Effect of personal and work stress on burnout, job satisfaction and general health of hospital nurses in South Africa. Health SA Gesondheid. 2017;22(1):252-8. https://doi.org/10.1016/j.hsa g.2016.10.001.

6. Luan X, Wang P, Hou W, Chen L, Lou F. Job stress and burnout: a comparative study of senior and head nurses in China. Nurs Health Sci. 2017;19(2):163-9. https://doi.org/10.1111/nhs.12328.

7. Van der Colff JJ, Rothmann S. Occupational stress, sense of coherence, coping, burnout and work engagement of registered nurses in South Africa. SA J Ind Psychol. 2009;35(1):1-10.

8. $\quad$ Epp K. Burnout in critical care nurses: a literature review. Dynamics. 2012; 23(4):25-31.

9. Frogli E, Rudman A, Lovgren M, Gustavsson P. Problems with task mastery, social acceptance, and role clarity explain nurses' symptoms of burnout during the first professional years: a longitudinal study. Work. 2019;62(4): 573-84. https://doi.org/10.3233/WOR-192892.

10. National Academies of Sciences Engineering Medicine. Taking action against clinician burnout: a systems approach to professional well-being. Washington (DC): National Academies Press (US); 2019.

11. Leiter MP. Burnout as a developmental process: consideration of models. Washington DC: Taylor \& Francis; 1993.

12. Khamisa N, Oldenburg B, Peltzer K, llic D. Work related stress, burnout, job satisfaction and general health of nurses. Int J Environ Res Public Health. 2015;12(1):652-66. https://doi.org/10.3390/ijerph120100652.
13. Garcia CL, Abreu LC, Ramos JLS, Castro CFD, Smiderle FRN, Santos JAD, et al. Influence of burnout on patient safety: systematic review and metaanalysis. Medicina (Kaunas). 2019;55(9):553. https://doi.org/10.3390/medicina 55090553.

14. Stamm BH. The concise ProQOL manual (2nd ed.). Pocatello, ID: Professional Quality of life (ProQOL). org; 2010.

15. Sacco TL, Copel LC. Compassion satisfaction: a concept analysis in nursing. Nurs Forum. 2018;53(1):76-83. https://doi.org/10.1111/nuf.12213.

16. Wang J, Okoli CTC, He H, Feng F, Li J, Zhuang L, et al. Factors associated with compassion satisfaction, burnout, and secondary traumatic stress among Chinese nurses in tertiary hospitals: a crosssectional study. Int J Nurs Stud. 2020;102:103472. https://doi.org/10.101 6/j.jinurstu.2019.103472.

17. Itzhaki M, Bluvstein I, Peles Bortz A, Kostistky H, Bar Noy D, Filshtinsky V, et al. Mental health nurse's exposure to workplace violence leads to job stress, which leads to reduced professional quality of life. Front Psychiatry. 2018:9:59. https://doi.org/10.3389/fpsyt.2018.00059.

18. Wu S, Singh-Carlson S, Odell A, Reynolds G, Su Y. Compassion fatigue, burnout, and compassion satisfaction among oncology nurses in the United States and Canada. Oncol Nurs Forum. 2016;43(4):E161-9. https://doi.org/1 0.1188/16.ONF.E161-E169.

19. Partlak Günüşen N, Üstün B, Serçekuş Ak P, Büyükkaya BD. Secondary traumatic stress experiences of nurses caring for cancer patients. Int J Nurs Pract. 2019;25(1):e12717. https://doi.org/10.1111/ijn.12717.

20. Slocum-Gori S, Hemsworth D, Chan WW, Carson A, Kazanjian A. Understanding compassion satisfaction, compassion fatigue and burnout: a survey of the hospice palliative care workforce. Palliat Med. 2013;27(2):1728. https://doi.org/10.1177/0269216311431311.

21. Zhou J, Yang Y, Qiu X, Yang X, Pan H, Ban B, et al. Serial multiple mediation of organizational commitment and job burnout in the relationship between psychological capital and anxiety in Chinese female nurses: a cross-sectional questionnaire survey. Int J Nurs Stud. 2018;83:75-82. https://doi.org/10.1016/ j.ijnurstu.2018.03.016

22. Zhang YY, Zhang C, Han XR, Li W, Wang YL. Determinants of compassion satisfaction, compassion fatigue and burn out in nursing: a correlative metaanalysis. Medicine (Baltimore). 2018;97(26):e11086. https://doi.org/10.1097/ MD.0000000000011086.

23. Hunsaker S, Chen HC, Maughan D, Heaston S. Factors that influence the development of compassion fatigue, burnout, and compassion satisfaction in emergency department nurses. J Nurs Scholarsh. 2015;47(2):186-94. https://doi.org/10.1111/jnu.12122.

24. Kelly L, Runge J, Spencer C. Predictors of compassion fatigue and compassion satisfaction in acute care nurses. J Nurs Scholarsh. 2015;47(6): 522-8. https://doi.org/10.1111/jnu.12162.

25. Mooney C, Fetter K, Gross BW, Rinehart C, Lynch C, Rogers FB. A preliminary analysis of compassion satisfaction and compassion fatigue with considerations for nursing unit specialization and demographic factors. J Trauma Nurs. 2017;24(3):158-63. https://doi.org/10.1097/JTN. 0000000000000284

26. Nantsupawat A, Kunaviktikul W, Nantsupawat R, Wichaikhum O-A Thienthong H, Poghosyan L. Effects of nurse work environment on job dissatisfaction, burnout, intention to leave. Int Nurs Rev. 2017;64(1):91-8. https://doi.org/10.1111/inr.12342

27. Cavanagh N, Cockett G, Heinrich C, Doig L, Fiest K, Guichon JR, et al. Compassion fatigue in healthcare providers: a systematic review and metaanalysis. Nurs Ethics. 2020;27(3):639-65. https://doi.org/10.1177/096973301 9889400.

28. Shin Y, Yoon G, Kim J, Lee N, Lee J, Kim J. Survey of health and medical personnel (Publication No. 2018-38). Seoul: Korean Institute for Health and Social Affairs; 2018.

29. von Elm E, Altman DG, Egger M, Pocock SJ, Gøtzsche PC, Vandenbroucke JP. Strengthening the reporting of observational studies in epidemiology (STROBE) statement: guidelines for reporting observational studies. Bmj. 2007;335(7624):806-8. https://doi.org/10.1136/bmj.39335.541782.AD.

30. Kim O, Ahn Y, Lee HY, Jang HJ, Kim S, Lee JE, et al. The Korea Nurses' health study: a prospective cohort study. J Women's Health (Larchmt). 2017;26(8): 892-9. https://doi.org/10.1089/jwh.2016.6048.

31. Belanger CF, Hennekens $C H$, Rosner B, Speizer FE. The nurses' health study. Am J Nurs. 1978;78(6):1039-40.

32. Professional quality of life scale (PROQOL). https://www.proqol.org/uploads/ ProQOL_5_English_Self-Score_3-2012.pdf. Accessed 15 January 2021. 
33. Kim YH, Kim SR, Kim YO, Kim JY, Kim HK, Kim HY. Influence of type D personality on job stress and job satisfaction in clinical nurses: the mediating effects of compassion fatigue, burnout, and compassion satisfaction. J Adv Nurs. 2017;73(4):905-16. https://doi.org/10.1111/jan.13177.

34. Cohen $\mathrm{S}$, Williamson G. Perceived stress in a probability sample of the United States. The social psychology of health. Thousand Oaks, CA, US: Sage Publications, Inc; 1988.

35. Rayan A, Sisan M, Baker O. Stress, workplace violence, and burnout in nurses working in king Abdullah medical city during Al-hajj season. J Nurs Res. 2019;27(3):e26. https://doi.org/10.1097/jnr.0000000000000291.

36. Lee JS, Joo EJ, Choi KS. Perceived stress and self-esteem mediate the effects of work-related stress on depression. Stress Health. 2013;29(1):75-81. https:// doi.org/10.1002/smi.2428.

37. Hayes AF. Introduction to mediation, moderation, and conditional process analysis: a regression-based approach: Guilford publications; 2017.

38. Hui Z, Dai $X$, Wang $X$. Mediating effects of empathy on the association between nursing professional values and professional quality of life in Chinese female nurses: a cross-sectional survey. Nurs Open. 2020;7(1):411-8. https://doi.org/10.1002/nop2.404.

39. Wu Y, Zheng J, Liu K, Baggs JG, Liu J, Liu X, et al. The associations of occupational hazards and injuries with work environments and overtime for nurses in China. Res Nurs Health. 2018;41(4):346-54. https://doi.org/10.1002/ nur.21882.

40. Griffiths P, Dall'Ora C, Simon M, Ball J, Lindqvist R, Rafferty AM, et al. Nurses' shift length and overtime working in 12 European countries: the association with perceived quality of care and patient safety. Med Care. 2014;52(11): 975-81. https://doi.org/10.1097/MLR.0000000000000233.

41. Cho E, Lee NJ, Kim EY, Kim S, Lee K, Park KO, et al. Nurse staffing level and overtime associated with patient safety, quality of care, and care left undone in hospitals: a cross-sectional study. Int I Nurs Stud. 2016;60:263-71. https://doi.org/10.1016/j.jpurstu.2016.05.009.

42. Cohen-Mansfield J. Stress in nursing home staff: a review and a theoretical model. J Appl Gerontol. 1995;14(4):444-66. https://doi.org/10.1177/0733464 89501400406.

43. Chen Y-P, Tsai J-M, Lu M-H, Lin L-M, Lu C-H, Wang K-WK. The influence of personality traits and socio-demographic characteristics on paediatric nurses' compassion satisfaction and fatigue. J Adv Nurs. 2018;74(5):1180-8. https://doi.org/10.1111/jan.13516.

44. Lin TC, Lin HS, Cheng SF, Wu LM, Ou-Yang MC. Work stress, occupational burnout and depression levels: a clinical study of paediatric intensive care unit nurses in Taiwan. J Clin Nurs. 2016;25(7-8):1120-30. https://doi.org/1 0.1111/jocn.13119.

45. Jennings BM. Work stress and burnout among nurses: role of the work environment and working conditions. In: Patient safety and quality: An evidence-based handbook for nurses. edn: Agency for Healthcare Research and Quality (US); 2008.

46. West CP, Dyrbye LN, Erwin PJ, Shanafelt TD. Interventions to prevent and reduce physician burnout: a systematic review and meta-analysis. Lancet. 2016;388(10057):2272-81. https://doi.org/10.1016/S0140-6736(16)31279-X.

47. Lombardo B, Eyre C. Compassion fatigue: a nurse's primer. Online J Issues Nurs. 2011;16(1):3. https://doi.org/10.3912/OJIN.Vol16No01Man03.

48. Kharatzadeh H, Alavi M, Mohammadi A, Visentin D, Cleary M. Emotional regulation training for intensive and critical care nurses. Nurs Health Sci. 2020;22(2):445-53. https://doi.org/10.1111/nhs.12679.

\section{Publisher's Note}

Springer Nature remains neutral with regard to jurisdictional claims in published maps and institutional affiliations.

Ready to submit your research? Choose BMC and benefit from:

- fast, convenient online submission

- thorough peer review by experienced researchers in your field

- rapid publication on acceptance

- support for research data, including large and complex data types

- gold Open Access which fosters wider collaboration and increased citations

- maximum visibility for your research: over $100 \mathrm{M}$ website views per year

At BMC, research is always in progress.

Learn more biomedcentral.com/submissions 